\title{
ENTRE NATURALIZAÇÕES E DESASSOSSEGOS: EDUCANDO PARA TOLERAR O INTOLERÁVEL?
}

\author{
ENTRE NATURALIZACIONES Y DESASOSIEGOS: EDUCANDO PARA \\ TOLERAR EL INTOLERABLE?
}

\author{
BETWEEN NATURALIZATION AND UNQUIETNESS: EDUCATING TO \\ TOLERATE THE INTOLERABLE?
}

Igor Vinicius Lima VALENTIM ${ }^{1}$

\begin{abstract}
RESUMO: Três cenas escritas a partir de vivências em uma universidade pública, localizada muito, muito distante de nós. Com a atenção voltada ao cotidiano e às relações acadêmicas desenvolvidas, este texto busca questionar, provocar e incitar reflexões a respeito do que produzimos na universidade enquanto estudantes, docentes e técnicos. Acostumamo-nos a fazer parte de universidades que investigam e analisam... os outros! Mas damos pouca atenção àquilo que fazemos, ao modo como o fazemos e ao que nossas atitudes suscitam, estimulam e produzem. Apoiado em referenciais teóricos ligados à micropolítica e à subjetividade, este texto utiliza a autoetnografia como método. Com narrativas autoetnográficas interrogo em que medida as relações acadêmicas - compreendidas enquanto processos de subjetivação - podem contribuir para a naturalização de situações que ameaçam a saúde e colocam em perigo as vidas de docentes, estudantes, técnicos, funcionários e demais envolvidos na Academia. O que já naturalizamos e sequer questionamos? O que estimulamos com nossas atitudes e relações? Que modos de gerir a universidade construímos? O que esses modos de gerir a educação superior estimulam? Estamos educando para que se tolere o intolerável?
\end{abstract}

PALAVRAS-CHAVE: Educação superior. Autoetnografia. Relações acadêmicas.

RESUMEN: Tres escenas escritas a partir de vivencias en una universidad pública, ubicada en un lugar muy, muy lejos de nosotros. Con la atención orientada a lo cotidiano y a las relaciones académicas desarrolladas, este texto busca cuestionar, provocar y incitar reflexiones acerca de lo que producimos en la universidad como estudiantes, profesores y técnicos. Nos acostumbramos a participar de universidades que investigan y analizan ... los demás. Pero damos poca atención a lo que hacemos, al modo como lo hacemos y lo que nuestras actitudes suscitan, estimulan y producen. Apoyado en referenciales teóricos ligados a la micropolítica y a la subjetividad, este texto utiliza la autoetnografía como método. Con narrativas autoetnográficas interrogo en qué medida las relaciones académicas - comprendidas como procesos de subjetivación - pueden contribuir a la naturalización de situaciones que amenazan la

\footnotetext{
${ }^{1}$ Universidade Federal do Rio de Janeiro (Ufrj), Rio de Janeiro - RJ - Brasil. Universidade Federal Fluminense (Uff), Niterói - RJ - Brasil. Professor no Departamento de Administração Educacional da Faculdade de Educação da Universidade Federal do Rio de Janeiro e do Programa de Pós-Graduação em Educação da Universidade Federal Fluminense, e membro do CSG, SOCIUS, ISEG da Universidade de Lisboa, Portugal. Email: valentim@gmail.com.
}

RPGE - Revista on line de Política e Gestão Educacional, Araraquara, v. 22, n. esp.1, p. 265-279, mar., 2018. 
salud y ponen en peligro las vidas de docentes, estudiantes, técnicos, funcionários y demás participantes de la Academia. ¿Qué ya naturalizamos y ni siquiera cuestionamos? ¿Qué estimulamos con nuestras actitudes y relaciones? ¿Qué modos de gestionar la universidad construimos? ¿Qué estimulan estos modos de gestionar la educación superior? ¿Estamos educando para que se tolere lo intolerable?

PALABRAS-CLAVE: Educación superior. Autoetnografía. Relaciones académicas.

ABSTRACT: Three scenes written from experiences in a public university, located far, far away from us. With the attention focused on the daily academic life and on the academic relations developed, this text seeks to question, to provoke and to incite reflections about what we produce in the university as students, teachers and technicians. We get used to being part of universities that investigate and analyze ... others! But we pay little attention to what we do, to how we do it, and to what our attitudes elicit, stimulate, and produce. Based on theoretical concepts such as micropolitics and subjectivity, this text uses autoethnography as its method. With autoethnographic narratives I question the extent to which academic relations understood as processes of subjectivation - can contribute to the naturalization of situations that threaten health and endanger the lives of teachers, students, technicians, employees and others involved in the Academy. What have we naturalized and do not even question? What do we stimulate with our attitudes and relationships? What ways of managing the university do we build? What do these modes Higher Education management stimulate? Are we educating to tolerate the intolerable?

KEYWORDS: Higher education. Autoethnography. Academic relations.

\section{Introdução}

Estamos acostumados a fazer parte de universidades públicas que, de forma competente, analisam, pesquisam, investigam [...] os outros! Mas nos propomos pouquíssimo a dar atenção àquilo que fazemos, a olhar criticamente o que nossas atitudes suscitam e os modos como nos relacionamos e realizamos nossos trabalhos na Academia.

Existem diversas maneiras de olhar, investigar, problematizar, provocar, refletir e escrever a respeito do que estamos produzindo na universidade. Este artigo que aqui se inicia está voltado aos cotidianos da Academia em sua dimensão majoritariamente micropolítica, especialmente ao que se refere às ações diárias, ao que estamos produzindo nas relações acadêmicas, a partir de nossos olhares, comportamentos, decisões, omissões, subjetividades. Apesar de discutir o cotidiano, cabe ressaltar, este texto não traz respostas prontas e muito menos sugere modelos padronizados de comportamentos.

RPGE - Revista on line de Política e Gestão Educacional, Araraquara, v. 22, n. esp.1, p. 265-279, mar., 2018. 
Parto do entendimento que a universidade não constrói apenas conhecimentos, mas (re)produz valores, modos de pensar, sentir, lidar com os outros e enxergar a si. No âmbito deste trabalho, utilizo o conceito de subjetividade para expressar as maneiras pelas quais os sujeitos fazem experiência de si (FOUCAULT, 1999). Essas subjetividades são produzidas por meio de processos - processos de subjetivação - que Deleuze (1992, p. 142) trata como "produção dos modos de existência ou estilos de vida".

De modo mais específico, busco com este texto interrogar em que medida as relações acadêmicas que estabelecemos podem estar, enquanto processos de subjetivação, contribuindo para a naturalização de situações degradantes, perigosas e ameaçadoras à nossa saúde, às nossas vidas, bem como às de estudantes, técnicos educacionais, funcionários e demais envolvidos na vida universitária.

Temas como o cotidiano acadêmico e a produção de subjetividades precisam ser mais discutidos. Para tanto, trato das conexões entre as relações acadêmicas e os modos de estar na e de gerir a educação 'superior' que diariamente construímos. Quais serão, então, os nossos papéis enquanto acadêmicos se silenciarmos e não discutirmos criticamente esses fenômenos a partir de nossos próprios exemplos daquilo que nós mesmos fazemos? Que sentido faz prescrevermos teorias e análises, que em tese servirão para outras pessoas, sem que isso dialogue com o que fazemos? Faça o que eu digo, não faça o que eu faço?

É interessante a observação de Sílvio Gallo (2008, p. 65) de que enquanto uma educação maior é produzida "na macropolítica, nos gabinetes, expressa nos documentos", existe também uma educação menor, que está no âmbito da micropolítica, "na sala de aula, expressa nas ações cotidianas de cada um", e na qual os envolvidos agem "nas micro-relações cotidianas, construindo um mundo dentro do mundo, cavando trincheiras de desejo".

A questão micropolítica está, aqui, ligada ao que se passa no âmbito do sensível, do invisível, do que é muitas vezes indizível: um plano de intensidades e sensações que “é acessado sobretudo pela percepção e o segundo, pela sensação", que "é efeito das forças do mundo tal como afetam nossos corpos, produzindo estranhamento e pondo em crise o referido repertório" (ROLNIK, 2008, s. p.).

\section{Caminhos metodológicos}


Para atingir o objetivo proposto, desenho caminhos com o auxílio da autoetnografia. O método autoetnográfico está relacionado à construção de narrativas que, ao contrário da etnografia tradicional, não separam o observador do observado, não acreditam em uma suposta neutralidade, e nem buscam produzir descrições de objetos déjà-là, à espera de serem coletados ou descobertos. No âmbito das produções autoetnográficas, toda estória construída “é parcial, privilegiada e retoricamente construída para um público" (ADAMS; HOLMAN JONES; ELLIS, 2015, p. 82). Portanto, o pesquisador está sempre implicado naquilo que pesquisa e produz.

$\mathrm{Na}$ forma do que expus acima, não cabe se falar em desprendimento, neutralidade ou distanciamento como critérios para avaliar a qualidade ou o rigor metodológico do que aqui produzo. O conceito de rigor acadêmico está ligado, neste texto, ao seu potencial de afetação: como ele pode afetar, produzir novas reflexões, angústias e inquietações que conduzam a ações? Rigor, neste sentido, ligado à produção de desassossegos ao abordar temas delicados, polêmicos e muitas vezes silenciados nas investigações e publicações acadêmicas.

Autoetnografias são construídas com pensamentos, sentimentos, sensações e experiências que nos trazem dúvidas e incertezas (VALENTIM, 2016). Por vezes, elas nos fazem questionar "nossos entendimentos de nós próprios, de outros e de nossos mundos" (ADAMS; HOLMAN JONES; ELLIS, 2015, p. 47). Daniela Versiani é uma rara pesquisadora nacional que escreve a respeito da autoetnografia enquanto método de pesquisa. De acordo com ela (VERSIANI, 2005, p. 101), o método tenta lidar com o "reconhecimento da subjetividade como fator importante no processo de construção de conhecimento".

Especificamente neste texto, a autoetnografia ganha um sentido político ao colocar sob atenção sujeitos, tradições, instituições e relações no mundo acadêmico, sem uma preocupação maior com questões jurídicas e/ou legais, bem como sem entender lógicas macro como capazes de explicar tudo o que se passa.

É importante ressaltar que, assim como em qualquer texto autoetnográfico, não há a preocupação em estabelecer verdades únicas e imutáveis. De acordo com o método utilizado, o que escrevo não carrega pretensões generalizantes nem de ser uma representação 'fiel' e/ou 'verdadeira' de todas as universidades. Nem sequer de uma universidade, faculdade ou departamento específico. A autoetnografia me ajuda a colocar em foco o que me passa, o que me acontece, e em colocar isso em movimento e em diálogo com contextos, relações e subjetividades construídas.

RPGE - Revista on line de Política e Gestão Educacional, Araraquara, v. 22, n. esp.1, p. 265-279, mar., 2018. 
Utilizo as mencionadas inspirações autoetnográficas para construir narrativas a partir de experiências no cotidiano de uma universidade pública localizada muito, muito distante de nós, a qual opto por preservar o anonimato. Tento ter o cuidado de que sejam preservadas as pessoas, sem exposições desnecessárias.

Construo a seguir três breves cenas do cotidiano universitário. Utilizá-las-ei como ferramentas de análise a respeito das relações que estabelecemos uns com os outros e, por conseguinte, do que construímos no cotidiano da Academia, de como habitamos e gerimos a educação 'superior' e a nós mesmos.

\section{Cena 1}

Quase tudo pronto para o início da aula noturna, que será ministrada por uma professora que trabalha na universidade há aproximadamente seis anos. A sala de aula não é muito espaçosa. Com formato retangular, possui capacidade aproximada de cinquenta lugares e um quadro branco preso à parede, bem próximo à porta, logo à direita da entrada. A sala está muito quente. É quase verão na cidade e a alta umidade deixa a sensação térmica ainda maior. Não há ar condicionado na sala; apenas um único ventilador, apoiado em um tripé, próximo ao quadro branco.

Das cinquenta cadeiras, quarenta já estão ocupadas no horário de início da aula. A professora se encaminha para a lateral da sala e, ao abrir a janela de madeira, o vidro quebra e cai, em pedaços, em cima dela. Sangue. Com cortes no braço e no pé, a docente é levada às pressas para receber atendimento médico. Pontos. Curativos. Nada de aula por hoje.

É esta sala que continuará abrigando a disciplina? Outras atividades continuarão sendo desenvolvidas com a sala nestas condições? Até quando? Até termos uma vítima fatal? Talvez nem assim.

Silenciamos. O assunto não vira tema de reclamação nem por parte da própria professora. Muito menos de discussão coletiva na instituição.

A professora estará totalmente recuperada para a próxima semana? Quais serão os impactos do ocorrido para a sua saúde futura? Ela está amparada institucionalmente após o ocorrido? Foi registrado o acidente de trabalho? Fica a pergunta no ar.

- Que bobagem! O importante é que ela não sofreu nada mais grave. 'Acidentes' acontecem. É assim mesmo. Não tem problema, semana que vem a aula retorna normalmente, no mesmo horário, no mesmo local, nas mesmas instalações. 


\section{Cena 2}

Idas e vindas pelos corredores da universidade. Um professor vai até uma das salas buscar um projetor multimídia para usar em sua aula vespertina, a ser desenvolvida em um espaço que ainda não tem o equipamento instalado.

Ao encontrar uma docente no caminho para a sala, os dois param para conversar no corredor, encostados a uma pilastra. Após menos de dois minutos de papo, parte do reboco cai do teto. Sem tempo de reação ou esquiva, o pedaço de concreto resvala no braço esquerdo da professora antes de se espatifar no chão. Cortes. Arranhões. Escoriações. Por alguns poucos centímetros, o pedaço de concreto, tijolos e tinta branca não atingiu a cabeça da funcionária.

É seguro que alunos, técnicos, professores, visitantes, animais, enfim, é seguro que seres vivos continuem transitando por um prédio nestas condições? Até quando continuaremos contando com a sorte? Até termos alguma vítima fatal? Ou nem assim pararemos e questionaremos a falta de condições mínimas de segurança?

- O importante é que ela não sofreu nada grave! Que 'sorte'! Vamos isolar esse canto do corredor com uma fita amarela para que ninguém mais passe por essa parte e encoste nessa pilastra. De resto, vida normal!

Até quando contaremos com a 'sorte'?

\section{Cena 3}

Chove muito. Relâmpagos e trovões. O vento forte nessa noite acaba por não só balançar as árvores do lado de fora do prédio, como também por trazer boa parte da chuva para dentro do recinto, tendo em vista que não há vedação adequada (para não falar dos diversos buracos e vidros quebrados) nas janelas.

A chuva invade também os corredores. São dezenas de colunas d'água vindas diretamente do teto gotejante. Cascatas? Cachoeiras? Nunca me recordo bem quais as diferenças entre elas. Funcionários terceirizados - da empresa contratada de serviços gerais responsável pela limpeza do prédio - se apressam em posicionar estrategicamente diversos baldes no chão. Em uma contagem rápida, ao passar por alguns dos corredores, não é exagero afirmar que são dezenas de baldes, obstáculos dos quais as pessoas precisam se desviar ao caminharem.

Não demoro a ouvir:

RPGE - Revista on line de Política e Gestão Educacional, Araraquara, v. 22, n. esp.1, p. 265-279, mar., 2018. 
- Ruim com os baldes, pior sem eles, afinal, se molhar ainda mais o piso, a situação pode se agravar e se tornar perigosa (ainda mais?).

Alunos e alunas, professores e professoras, vão chegando para suas aulas, projetos, orientações e demais atividades no prédio. Muitos encontram cadeiras molhadas, armários encharcados, computadores cobertos com lonas plásticas, e diversos espaços inabitáveis.

- Será que não tem perigo ficar aqui dentro com toda essa chuva? E o sistema elétrico? Será que corremos o risco de, a qualquer momento, misturar água e sistema elétrico? Temos algum sistema de proteção contra incêndios? E o reboco? E o telhado? Há rota de saída de emergência em caso de incêndio?

- Que nada! Isso está assim faz tempo! Já nos acostumamos! O importante é a gente desviar dessas goteiras e ter cuidado para não escorregar nas poças. Não podemos parar simplesmente por isso!

Coreografias dançantes entre baldes educadores.

\section{Algumas reflexões}

O que os modos como lidamos com as três situações acima narradas e as maneiras pelas quais nos relacionamos, nos espaços anteriormente ilustrados, dizem a respeito do que estimulamos e construímos na universidade, seja como estudantes, técnicos ou docentes?

Em primeiro lugar parece importante que cada um de nós faça uma reflexão: consideramos que existem, de fato, problemas nas situações narradas nas cenas? Pelo comportamento de boa parte dos integrantes da comunidade acadêmica envolvidos nas três cenas narradas, parece estar em curso uma naturalização das situações que faz com que tudo seja encarado como normal, natural, como fazendo parte do trabalho em uma universidade pública.

Se, por ventura, a leitora ou o leitor ainda não viver a citada naturalização e encontrar problemas nas situações experienciadas, entrará em foco uma segunda questão que parece pouquíssimo discutida na Academia: como avaliar e lidar com os problemas narrados?

Para alguns dos integrantes da Academia, a naturalização de estudar, trabalhar, conviver e habitar espaços físicos nas condições descritas anteriormente é algo quase esperado, tendo em vista que se trata de uma universidade pública no Brasil: 
- A universidade pública no Brasil é assim. Aqui não é a Suíça e nem temos recursos privados.

Reforça-se a ideia de que os integrantes das comunidades acadêmicas das universidades públicas brasileiras devem se acostumar a trabalhar/estudar sob condições precárias, indignas, inseguras, perigosas e, em muitos casos, sob concreta ausência de condições mínimas de segurança, habitabilidade, estudo e/ou trabalho.

A naturalização não é a única forma de conviver com as condições narradas. Há diversos acadêmicos que, abertamente, criticam a falta de investimentos em infraestrutura nas universidades públicas brasileiras como causa de quase todos os males que enxergam na Academia. Orçamentos cada vez mais reduzidos por parte do Estado são geralmente a explicação mais fácil e simples para problemas como os elencados nas três cenas apresentadas anteriormente. Esta é também uma razão que boa parte de estudantes, técnicos e docentes da própria Academia está acostumada a usar como justificativa para as mazelas, precarizações e perigos que vivemos em nosso cotidiano universitário. A 'culpa' é sempre dos outros, a responsabilização é sempre atribuída aos outros e outras, sejam instituições, pessoas ou projetos em curso.

- É tudo culpa do Banco Mundial. Das privatizações. Do projeto do capital.

Parece difícil não perceber e/ou não admitir que os significativos cortes orçamentários que a educação e a ciência no Brasil têm enfrentado, especialmente nos últimos anos, impactam significativamente o funcionamento das universidades públicas nacionais (ANDES-SN, 2017; SGUISSARDI; SILVA JÚNIOR, 2009). Acumulam-se e avolumam-se dívidas, cortam-se verbas de assistência estudantil e bolsas, reduzem-se os recursos destinados a investimentos e obras. Em muitos casos, as condições materiais mínimas para o funcionamento de universidades públicas brasileiras cada vez se encontram mais ameaçadas.

Não restam dúvidas que, com investimentos maciços em infraestrutura, seria possível consertar telhados, pisos, trocar janelas, instalar aparelhos de projeção e de arcondicionado, realizar obras em paredes e pilastras, dentre outras tantas necessidades urgentes enfrentadas por numerosos prédios de universidades públicas espalhadas pelo Brasil. Entretanto, os problemas suscitados pelas três cenas narradas neste artigo começam a ganhar contornos mais complexos e de explicações menos imediatas quando nos atentamos ao que se passa em termos das relações entre os envolvidos e das subjetividades produzidas nestas relações. A parcela ausente dessas análises parece residir justamente na ausência da autocrítica. Ou seja, é tudo de responsabilidade dos

RPGE - Revista on line de Política e Gestão Educacional, Araraquara, v. 22, n. esp.1, p. 265-279, mar., 2018. 
outros? Qual a nossa parcela de responsabilidade? O que as nossas atitudes, e não as teorias que utilizamos, estão produzindo? O que, em nossos comportamentos, pode ser modificado? Concordo com Santos (1997, p. 20) quando ele afirma que "talvez seja até muito mais fácil culpar o mundo em que vivemos, em vez de culpar a universidade" e a nós mesmos.

É preciso nos questionarmos, enquanto integrantes de universidades públicas, o que estimulamos em termos de modos de ser, estar, sentir e trabalhar na Academia quando silenciamos e/ou nos omitimos frente a tantas situações como as narradas anteriormente. Ou quando aceitamos e seguimos a vida 'normalmente' como se nada tivesse ocorrido. Façamos um exercício simples. Nos coloquemos por um minuto na posição de quem ocupa o cargo de Ministro da Educação, ou de Reitor ou Pró-Reitor de uma universidade pública, ou ainda mesmo de Diretor de uma unidade acadêmica dessa universidade. Qual a mensagem que receberíamos a respeito do que está acontecendo? Absolutamente nenhuma anormalidade. A mensagem de que tudo está correndo bem, funcionando normalmente, dentro de uma prática cotidiana aceitável. Não há situações emergenciais, não há demandas urgentes, não há riscos de vida (ou de morte) nem condições que colocam em risco milhares de integrantes das comunidades acadêmicas, já que tudo segue funcionando.

Tratando violência como sinônimo de afetação, incômodo, angústia, desassossego, concordo que "sem que nenhuma violência se exerça sobre elas, as pessoas se conformam a regras, seguem costumes que lhes parecem evidentes" (VEYNE, 2011, p. 167). O que estamos produzindo e ensinando com nossas atitudes e ações na/com a Academia? O que estimulamos? Que subjetividades estamos ajudando a produzir? Será que tudo o que foi narrado nas cenas não foi violência suficiente para provocar ações que fujam do conformismo?

\footnotetext{
Instalou-se, nos ambientes acadêmicos, um mal-estar que se impõe de maneira sutil e dissimulada. Sofre-se, mas nem sempre se percebe o sofrimento. Sente-se o incômodo, mas nem sempre se consegue apreender de onde ele provém. Estudantes, funcionários e professores tendem a transferir para outros planos a responsabilidade pelo que os aflige: culpam os maus dirigentes, o despreparo dos estudantes, as falhas do ensino médio, a escassez de recursos, os excessos da burocracia ou a incúria governamental [...]. A comunidade acaba por ficar prostrada, incapaz de reação inteligente. [...] Está se perdendo a capacidade de dizer não e propor alternativas (NOGUEIRA, 2005, s. p., grifos meus).
} 
Penso na formação de estudantes, uma das missões de uma universidade. Penso na produção de modos de ser, estar, sentir, estudar, trabalhar, enxergar a si e aos outros: penso em uma formação universitária como produção de subjetividades (DIAS, 2014) e, simultaneamente, na produção de subjetividades que ocorre nas relações acadêmicas, quase não discutida na literatura acadêmica brasileira.

Em trabalho anterior (VALENTIM, 2016), já apontei que, em muitos momentos, alguns acadêmicos consideram que não é interessante que as universidades públicas olhem para si próprias de forma crítica e analisem seus próprios modus operandi, sendo mais interessante que busquem realizar suas pesquisas a respeito de outras universidades e ainda outras organizações. Entretanto, concordo com o caráter imprescindível, fundamental, até mesmo para a sobrevivência das universidades, de desenvolverem investigações sobre o que fazem, produzem e como funcionam, já que

[a] universidade, aliás, é, talvez, a única instituição que pode sobreviver apenas se aceitar críticas, de dentro dela própria, de uma ou outra forma. Se a universidade pede aos seus participantes que calem, ela está se condenando ao silêncio, isto é à morte, pois seu destino é falar. A fidelidade reclamada não pode ser à universidade, e a ela não temos razão para ser fiéis. Nossa única fidelidade é com a idéia de universidade (SANTOS, 1997, p. 17).

Não parece mera coincidência quando Simões (2007, p. 307) aponta que muitos estudantes passam pela universidade anestesiados "por discursos e modelos imobilizadores", bem como "aderindo à rotina daqueles que fazem da universidade um lugar conservador, reservando às contestações um passado cômodo e pacificando a política em departamentos, programas e salas de aula". Não é exagero afirmar que uma boa parte de estudantes, professores e técnicos também passa pela universidade da mesma forma, presa a conformismos, costumes e a explicações do tipo de que "sempre foi assim”.

Inspirado no intelectual brasileiro Maurício Tragtenberg, Antônio Ozaí da Silva considera que

[p]ersistem práticas e atitudes delinquentes e com o agravante de que parecem naturalizadas e aceitas como necessárias e "normais". Perdese a capacidade de escandalizar-se e encontram-se argumentos racionais para legitimá-las. Não é fácil resistir à pressão pela adaptação. Vivemos a contradição da obediência à autoridade racional burocrática, às exigências inerentes à sobrevivência pessoal e acadêmica e, simultaneamente, a consciência da necessidade de negar e criticar o campo do qual somos partes. Eis o paradoxo do intelectual que, apesar de tudo, insiste em não se submeter (SILVA, 2008, p. 9).

RPGE - Revista on line de Política e Gestão Educacional, Araraquara, v. 22, n. esp.1, p. 265-279, mar., 2018. 


\section{Considerações}

É preciso fazer algo, provocar algo diferente do que está posto e aparente. O teto cai, a janela quebra, pessoas ficam feridas, fiação elétrica prestes a causar um incêndio com chuvas, e em nada se alteram rotinas? Ninguém se mobiliza? Até quando trataremos todos esses acontecimentos como meras fatalidades a respeito das quais não podemos fazer nada? Como acidentes? Até quando insistiremos em colocar a responsabilidade sempre nos outros, sejam eles investimentos, verbas, sem olharmos criticamente para nossas atitudes e em que medida elas contribuem para o que acontece? Para o que estamos educando? Em que tem contribuído a forma como gerimos a nossa própria vida?

Tragtenberg já discorria sobre o que chamou 'delinquência acadêmica', caracterizada pela doença que é a separação entre o fazer e o pensar. Ele já vislumbrava a enorme distância entre o que se fala e o que se faz na Academia, 'faça o que eu digo, não faça o que eu faço': afirmava a respeito da necessidade de se fomentar a crítica dentro das próprias universidades quando dizia, se referindo ao que ocorre dentro destas organizações, que "o falar é às vezes muito para frente e o fazer às vezes muito para trás” (TRAGTENBERG, 2012, p. 204). Não obstante, ele apontou que a universidade estimula seus integrantes a discutir os "meios sem nunca questionar os fins, a transformar os problemas políticos em problemas técnicos, a desprezar a consulta pública preferindo as soluções de gabinete, consumando o que definiríamos como traição dos intelectuais" (idem, p. 204-205).

Penso nas palavras de Peter Pál Pelbart (2013, p. 30) quando ele afirma que "cabe perguntar o que poderia ainda sacudir-nos de tal estado de letargia e se a catástrofe não estaria aí instalada cotidianamente [...], ao invés de ser ela apenas a irrupção súbita de um ato espetacular". É preciso provocar algo diferente, nem que seja em uma pessoa apenas. De uma em uma. Um contágio possível. O que não podemos mais é continuar calados, naturalizando tudo isso que está acontecendo há (muitos e muitos) meses.

Onde não há crítica, não há ciência. Por isso que a crítica no espaço universitário é fundamental, é o oxigênio da universidade. No dia em que se acabar com a crítica, a universidade se torna um cemitério de vivos. Torna-se aquela universidade do 'sim, senhor' (TRAGTENBERG, 2012, p. 133).

É preciso desnaturalizar o que parece - mas nada tem de - natural. Coisas que assumimos na nossa sociedade e nos nossos espaços educativos como óbvias, naturais, 
normais ou inevitáveis, mas que não o são, pois são "o resultado de decisões humanas que poderiam ter sido tomadas noutro sentido" (JARDINE, 2007, p. 16). O que mais me perturba é a indiferença quando reparo a cooptação de tantos e tantas colegas ao integrarem-se ao automatismo moral (PÁL PELBART, 2013, p. 139). Ou, como dizia Nietzsche (2008, p. 40), ao que se constrói como "indiscutibilidade dos costumes", que em nada se relacionam às experiências das pessoas, mas à tradição, à antiguidade e à santidade; à nossa anestesia, às anestesias construídas em nós.

Como o brilhante geógrafo brasileiro Milton Santos já comentava desde agosto de 1997 em comunicação proferida na Associação de Docentes da Universidade de São Paulo, ser "intelectual é exercer diariamente rebeldia contra conceitos assentados, tornados respeitáveis, mas falsos. É, também, aceitar o papel de criador e propagador do desassossego e o papel de produtor do escândalo, se necessário" (SANTOS, 1997, p. 18).

Parece que adiantará de pouco focarmos apenas em ter esperança ou desesperança, ou em sermos otimistas ou pessimistas (ROLNIK, 1995, s.p.); parece ainda mais necessário buscar rompermos com a anestesia que se instaura em nós em muitos momentos e aprendermos a caminhar mesmo em meio ao caos e ao desequilíbrio. Questionar, problematizar e desnaturalizar o que acontece hoje na universidade, principalmente pública, é fundamental para podermos "agitar o que está imóvel” (SIMÕES, 2007, p. 309). Precisamos refletir que este imóvel muitas vezes está paralisado em nós mesmos, quando nos submetemos ou estimulamos tradições, a reprodução acrítica de comportamentos e "pompas acadêmicas" (idem), vivendo na Academia uma vida avessa à experimentação do diferente, do novo, presa à domesticações e certezas.

Estando aberto ao novo, à experimentação, e agindo de modos diferentes e construindo problemas diferentes no cotidiano acadêmicos é que poderemos forjar outras formas de nos relacionarmos, de convivermos, de trabalharmos e, da mesma forma, de gerirmos e administrarmos a/na Educação Superior e à nós mesmos. Não temos como saber de antemão o que é possível fazer, o que é possível inventar. Como alerta Dias (2014, p. 422-423), precisamos nos arrancar de nós mesmos "para experimentar a relação com a alteridade, com o mundo, com a vida. [...] Talvez seja preciso acreditar mais no possível para que se possa inventá-lo”. Somente na experimentação é que descobriremos. E usar uma ou outra teoria, uma ou outra escola teórica, repetir as palavras de um ou outra autora não é suficiente. Essa experimentação 
é algo que precisamos encarnar. Na pele. Em nossa pele. Em nossas atitudes. Em nossas relações uns com os outros.

Considero importante, fundamental, a responsabilização dos envolvidos em situações vividas no cotidiano universitário que trazem impactos para as vidas dos demais envolvidos, uma vez que, embora não nos demos conta, somos em maior ou menor medida corresponsáveis pelo que vivemos. Entretanto, de acordo com a finalidade deste texto, é importante ressaltar que não nos adiantará enxergar uns aos outros como inimigos, este ou aquele gestor como "o" problema a ser solucionado, este ou aquele grupelho, este ou aquele sindicato. Como Guattari e Rolnik (2007, p. 156) bem já nos alertaram, o inimigo aqui se encarna justamente em nossos amigos e, principalmente, em nós mesmos: "a questão micropolítica é a de como reproduzimos (ou não)" determinados modos de subjetivação dominantes. Não adianta apontar o dedo para criticar ações de outros que nós mesmos repetimos ou apoiamos em nossas atitudes cotidianas, inclusive nas supostamente críticas e em prol de revoluções. Ou quando silenciamos em prol de joguetes e politicagens.

Também não adianta esperarmos por heróis. Vidas em risco. Riscos naturalizados. Qual a nossa parcela nisso tudo? É preciso analisar onde estamos nos omitindo e naturalizando. E, especialmente estando em universidades, parece ainda mais urgente questionar em que medida estamos estimulando, com nossas atitudes, a banalização de condições de trabalho e de vida intoleráveis e indignas, estimulando que outras pessoas também o banalizem e naturalizem. Entre naturalizações e desassossegos, em que medida estamos educando para tolerar o intolerável?

Agradecimentos: Fundação de Amparo à Pesquisa do Estado do Rio de Janeiro (FAPERJ), Brasil, e Fundação para a Ciência e a Tecnologia (FCT), Portugal, no âmbito do Projecto UID/SOC/04521/2013.

\section{REFERÊNCIAS}

ADAMS, Tony.; HOLMAN JONES, Stacy.; ELLIS, Carolyn. Autoethnography. New York: Oxford University Press, 2015.

ANDES-SN. Sindicato Nacional dos Docentes das Instituições de Ensino Superior. Cortes orçamentários ameaçam funcionamento das Instituições Federais de Ensino. 21 jul. 2017. Disponível em: <http://portal.andes.org.br/andes/print-ultimasnoticias.andes? $\mathrm{id}=8942>$. Acesso em: 01 ago. 2017. 
DELEUZE, Gilles. Conversações. São Paulo: Ed. 34, 1992.

DIAS, Rosimeri de Oliveira. Vida e resistência: formar professores pode ser produção de subjetividade? Psicologia em Estudo, v. 19, n. 3, p. 415-426, jul./set,. 2014.

FOUCAULT, Michel. La creación de modos de vida. Estética, ética y hermenéutica. Barcelona: Paidós, 1999.

GALLO, Sílvio. Deleuze e a Educação. 2. ed. Belo Horizonte: Autêntica, 2008.

GUATTARI, Félix.; ROLNIK, Suely. Micropolítica: cartografias do desejo. 8. ed. Petrópolis, RJ: Vozes, 2007.

JARDINE, Gail McNicol. Foucault e educação. Mangualde: Edições Pedago, 2007.

NIETZSCHE, Friedrich. Aurora. 2. ed. São Paulo: Escala, 2008.

NOGUEIRA, Marco Aurélio. Sofrimento organizacional, democracia e gestão universitária. In: TÓVOLI, Emília M. Gaspar.; SEGATTO, José A.; NOGUEIRA, Marco Aurélio (Orgs.). Gestão Universitária. Araraquara: Laboratório Editorial/Cultura Acadêmica, 2005, p. 19-67. Disponível em: <https://labpolitica.files.wordpress.com/2010/01/nogueira-marco-aurelio-sofrimentoorganizacional-democracia-e-gestao-universitaria.pdf>. Acesso em: 20 set. 2017.

PÁL PELBART, Peter. O avesso do niilismo: cartografias do esgotamento. São Paulo: n-1 edições, 2013.

ROLNIK, Suely. À sombra da cidadania: alteridade, homem da ética e reinvenção da democracia. Núcleo de Estudos da Subjetividade da PUC/SP, 1995. Disponível em: <www.pucsp.br/nucleodesubjetividade/Textos/SUELY/homemetica.pdf >. Acesso em: 08 jun. 2010.

ROLNIK, Suely. Desentranhando futuros. ComCiência - Revista Eletrônica de Jornalismo Científico, n. 99, 10 jun. 2008.

SANTOS, Milton. O intelectual e a universidade estagnada. Revista Adusp, n. 11, out. 1997, p. 17-20.

SGUISSARDI, Valdemar; SILVA JÚNIOR, João dos Reis. Trabalho intensificado nas federais: pós-graduação e produtivismo acadêmico. São Paulo: Xamã, 2009. $\mathrm{S}$

ILVA, Antonio Ozaí da. Somos todos delinquentes acadêmicos? Revista Espaço Acadêmico, n. 88, set. 2008.

SIMÕES, Gustavo. Para agitar o que está imóvel. Verve, n. 12, out 2007, p. 307-309.

TRAGTENBERG, Maurício. Educação e burocracia. São Paulo: Editora UNESP, 2012. 
VALENTIM, Igor Vinicius Lima. Cafetinagem acadêmica: alguém tem medo de pesquisar as relações acadêmicas? Polêm!ca, v. 16, p. 19-36, 2016.

VERSIANI, Daniela Beccaccia. Autoetnografias: conceitos alternativos em construção. Rio de Janeiro: 7Letras, 2005.

VEYNE, Paul. Foucault: seu pensamento, sua pessoa. Rio de Janeiro: Civilização Brasileira, 2011.

\section{Como referenciar este artigo}

VALENTIM, Igor Vinicius Lima. Entre naturalizações e desassossegos: educando para tolerar o intolerável? Revista on line de Política e Gestão Educacional, Araraquara, v. 22, n. esp.1, p. 265-279, mar., 2018. E-ISSN:1519-9029.

Submetido em: 04/10/2017

Aprovado em: 14/12/2017 